\title{
Autophagy: process and function
}

\author{
Noboru Mizushima ${ }^{1}$ \\ Department of Physiology and Cell Biology, Tokyo Medical and Dental University, Tokyo 113-8519, Japan; Solution \\ Oriented Research for Science and Technology, Japan Science and Technology Agency, Tokyo 102-0075, Japan
}

\begin{abstract}
Autophagy is an intracellular degradation system that delivers cytoplasmic constituents to the lysosome. Despite its simplicity, recent progress has demonstrated that autophagy plays a wide variety of physiological and pathophysiological roles, which are sometimes complex. Autophagy consists of several sequential steps-sequestration, transport to lysosomes, degradation, and utilization of degradation products-and each step may exert different function. In this review, the process of autophagy is summarized, and the role of autophagy is discussed in a process-based manner.
\end{abstract}

Autophagy is a general term for the degradation of cytoplasmic components within lysosomes /Cuervo 2004; Levine and Klionsky 2004; Shintani and Klionsky 2004; Klionsky 2005, 2007; Mizushima and Klionsky 2007). This process is quite distinct from endocytosis-mediated lysosomal degradation of extracellular and plasma membrane proteins. There are three types of autophagymacroautophagy, microautophagy, and chaperone-mediated autophagy — and the term "autophagy" usually indicates macroautophagy unless otherwise specified (Fig. 1). Autophagy is mediated by a unique organelle called the autophagosome. As autophagosomes engulf a portion of cytoplasm, autophagy is generally thought to be a nonselective degradation system. This feature is in marked contrast to the ubiquitin-proteasome system, which specifically recognizes only ubiquitinated proteins for proteasomal degradation. It is therefore reasonable to assume that the ubiquitin-proteasome system has numerous specific functions because it can selectively degrade thousands of substrates.

However, recent studies have clearly demonstrated that autophagy has a greater variety of physiological and pathophysiological roles than expected, such as starvation adaptation, intracellular protein and organelle clearance, development, anti-aging, elimination of microorganisms, cell death, tumor suppression, and antigen presentation (Mizushima 2005). Additionally, in some situations, the contribution of autophagy seems to be very complicated. For example, it is very difficult to gen-

[Keywords: Autophagy; autophagosome; degradation; lysosome; amino acids]

${ }^{1}$ Correspondence.

E-MAIL nmizu.phy2@tmd.ac.jp; FAX 81-3-5803-0118.

Article is online at http://www.genesdev.org/cgi/doi/10.1101/gad.1599207. eralize the role of autophagy in cancer and cell death. This is like the question: "Is inflammation good or bad for life?" Of course, inflammation is required for the anti-bacterial response, but the inflammatory response associated with bacterial pneumonia can be life-threatening. Therefore, it may be difficult to draw simplified connections between autophagy and higher-order functions.

How can a bulk degradation system exert so many functions? One determinant is probably the extent of degradation. Too much destruction without construction would be harmful for cells. This may explain many of the controversial issues related to the toxicity of autophagy, particularly observed in cultured cells. However, the range of autophagy seems to be strictly controlled in vivo; autophagic activity or total proteolysis is not sustained, and decreases during prolonged starvation (Mortimore et al. 1983; de Waal et al. 1986; Mizushima et al. 2004).

To understand the various roles of autophagy, it may be useful to subclassify macroautophagy into "induced autophagy" and "basal autophagy" (Mizushima 2005). The former is used to produce amino acids following starvation, while the latter is important for constitutive turnover of cytosolic components. However, even this distinction is too simplified and cannot be applied to more complicated issues.

Autophagy consists of several sequential steps: sequestration, degradation, and amino acid/peptide generation. Each step seems to exert different functions in a variety of cellular contexts. These step-dependent functions may allow autophagy to be multifunctional. Thus, in this review, I will attempt to follow the role of autophagy in a process-based manner.

\section{The process of autophagy}

Induction of autophagy

The most typical trigger of autophagy is nutrient starvation; in this sense, lack of any type of essential nutrient can induce autophagy. In yeast, nitrogen starvation is the most potent stimulus, but withdrawal of other essential factors such as carbon, auxotrophic amino acids and nucleic acids, and even sulfate can induce autophagy, albeit less efficiently (Takeshige et al. 1992). Nitrogen or carbon starvation also triggers autophagy in plant cells (Moriyasu and Ohsumi 1996; Yoshimoto et al. 2004). 


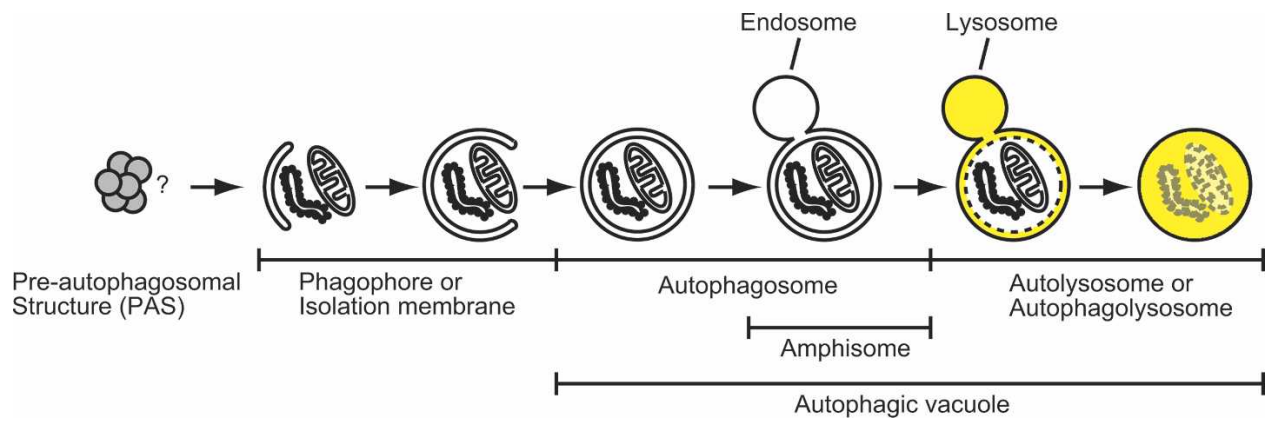

Figure 1. The process of macroautophagy in mammalian cells. A portion of cytoplasm, including organelles, is enclosed by a phagophore or isolation membrane to form an autophagosome. The outer membrane of the autophagosome subsequently fuses with the endosome and then the lysosome, and the internal material is degraded. In yeast, autophagosomes are generated from the PAS, which has not yet been identified in mammalian cells. The nomenclature for various autophagic structures is indicated.

In mammals, regulation of autophagy appears to be highly complicated. Depletion of total amino acids strongly induces autophagy in many types of cultured cells, but the effects of individual amino acids differ. Leu, Tyr, Phe, Gln, Pro, His, Trp, Met, and Ala suppress autophagy in ex vivo perfused liver (Mortimore and Pösö 1987). However, such profiles depend on cell type because amino acid metabolism differs greatly among tissues. For example, only leucine has a dominant effect on skeletal muscle and heart (Mortimore and Pösö 1987). How cells sense amino acid concentration is not fully understood. One candidate sensor is GCN2, a tRNAbinding protein kinase (Tallóczy et al. 2002), and recent reports suggest the presence of other amino acid signaling pathways involving class III phosphatidylinositol 3 (PI3)-kinase and Beclin 1 (Byfield et al. 2005; Nobukuni et al. 2005). However, the physiological significance of autophagy regulation by amino acid starvation has not yet been clarified. Changes in amino acid concentration in tissues and plasma during fasting are relatively small (Palou et al. 1981). In multicellular organisms, each cell would not necessarily sense nutrient availability. Rather, nutrient consumption is a problem for the organism, and it is therefore reasonable to think that autophagy should be regulated by a highly organized system. It is now believed that the endocrine system, particularly insulin, manages autophagy regulation in vivo. Liver autophagy is suppressed by insulin and enhanced by glucagon (Mortimore and Pösö 1987). Furthermore, recent Drosophila genetic studies have demonstrated the physiological importance of insulin signaling in vivo (Rusten et al. 2004; Scott et al. 2004). Other hormones and growth factors also seem to contribute to autophagy regulation. It is well known that serum starvation can induce autophagy in many types of cultured cell. The hematopoietic growth factor interleukin-3 (IL-3) suppresses autophagy through, at least in part, regulation of nutrient availability (Lum et al. 2005b; see below).

Amino acid and insulin/growth factor signals are thought to converge on mTOR (mammalian target of rapamycin), which is a master regulator of nutrient signaling. Indeed, treatment with inhibitors of TOR such as rapamycin and CCI-779 induces autophagy in yeast
(Noda and Ohsumi 1998) and even in animals (Ravikumar et al. 2004). However, not all autophagy signals are transduced through mTOR; some amino acid signaling can suppress autophagy in an mTOR-independent manner (Mordier et al. 2000; Kanazawa et al. 2004). More recently, small-molecule enhancers of the cytostatic effects of rapamycin (called SMERs) were identified to induce autophagy, which acts independently of mTOR (Sarkar et al. 2007).

In addition to insulin and amino acid signaling, the involvement of many other factors in autophagy regulation has recently been reported (Codogno and Meijer 2005). These include Bcl-2 (see below), reactive oxygen species (ROS) (Djavaheri-Mergny et al. 2006; ScherzShouval et al. 2007; Xiong et al. 2007b), calcium (HoyerHansen et al. 2007), AMP-activated protein kinase (AMPK) (Meley et al. 2006; Hoyer-Hansen et al. 2007; Liang et al. 2007), BNIP3 (Daido et al. 2004), p19 ARF (Reef et al. 2006), DRAM (Crighton et al. 2006), calpain (Demarchi et al. 2006), TRAIL (Mills et al. 2004), FADD (Pyo et al. 2005; Thorburn et al. 2005), and myo-inositol1,4,5-triphosphate ( $\mathrm{IP}_{3}$ ) (Sarkar et al. 2005; Criollo et al. 2007).

\section{Autophagosome formation}

Membrane dynamics during autophagy are highly conserved from yeast to plants and animals. In the first step of autophagosome formation, cytoplasmic constituents, including organelles, are sequestered by a unique membrane called the phagophore or isolation membrane, which is a very flat organelle like a Golgi cisterna. Complete sequestration by the elongating phagophore results in formation of the autophagosome, which is typically a double-membraned organelle. This step is a simple sequestration, and no degradation occurs. Where and how autophagosomes emerge has been a major question. In yeast, 31 Atg (autophagy-related) proteins have been identified, and many of them gather at a site that can be identified by fluorescence microscopy as a punctate spot very close to the vacuolar membrane. Since autophagosomes are generated from this site, it is called the "preautophagosomal structure (PAS)" (Kim et al. 2001; Su- 
zuki et al. 2001; Suzuki and Ohsumi 2007). Unfortunately, detailed structural information regarding the PAS is not currently available, and it is even unknown whether it is a membranous structure. Equivalent structures have not been observed in mammalian cells. Yeast cells may have a stable PAS because it is shared with the cytoplasm-to-vacuole targeting (Cvt) pathway, a constitutive transport pathway for amino peptidase 1 (Ape1) and $\alpha$-mannosidase (Ams1) from the cytosol to the vacuole (Klionsky and Ohsumi 1999).

Among the 31 Atg proteins, 18 Atg proteins-Atg1-10, Atg12-14, Atg16-18, Atg29, and Atg31-are involved in autophagosome formation and are called "AP-Atg proteins" (Klionsky et al. 2003; Kabeya et al. 2007; Suzuki and Ohsumi 2007). Since the function of these Atg proteins has been extensively reviewed (Klionsky 2005; Klionsky et al. 2007; Suzuki and Ohsumi 2007), only some topics are highlighted here. A recent systematic analysis showed that the AP-Atg proteins depend on each other for recruitment to the PAS (Suzuki et al. 2007); in particular, Atg17 was found to be a scaffold for PAS organization (Fig. 2). The recently identified Atg29 (Kawamata et al. 2005) and Atg31 (Kabeya et al. 2007) appear to function together with Atg17. Atg11 is also important for PAS organization but is essential only for the Cvt pathway (Suzuki et al. 2007). Other AP-Atg proteins target to the PAS as shown in Figure 2 and exert their own roles in autophagosome formation. Although the precise function of each protein remains to be understood, an unexpected function was shown for yeast Atg8. Atg8, a ubiquitin-like protein, is present on autophagic membranes as a phosphatidylethanolamine (PE)-conjugated form (Atg8-PE). Atg8 mediates tethering and hemifusion of liposomes containing Atg8-PE in an in vitro system (Nakatogawa et al. 2007). This unique membrane fusion process was proposed to account for membrane elongation of phagophore/isolation membranes in vivo.

Although many Atg proteins are conserved between yeast and mammals, several mammalian-specific factors that modulate the functions of Atg proteins have been identified. The most well studied is Beclin 1, which is a mammalian Atg6/Vps30 (vacuolar protein sorting 30) ortholog and a subunit of the class III PI3-kinase complex. Beclin 1 was originally identified as an interaction partner of Bcl-2, an anti-apoptotic protein (Liang et al. 1998). This Bcl-2-Beclin 1 interaction is mediated through a BH3 domain in Beclin 1 (Maiuri et al. 2007; Oberstein et al. 2007) and is reduced upon starvation, freeing Beclin 1 to activate autophagy (Pattingre et al. 2005; Maiuri et al. 2007). The endoplasmic reticulum (ER)-targeted but not mitochondrial-targeted Bcl-2 effectively suppresses autophagy (Pattingre et al. 2005; Criollo et al. 2007). The starvation-induced dissociation of Beclin 1 and Bcl-2 (or Bcl- $\mathrm{X}_{\mathrm{L}}$ ) could be one manner in which nutrient starvation induces autophagy. Therefore, it was proposed that Bcl-2 is not only an anti-apoptotic but also an anti-autophagic protein. Alternatively, Bcl-2 was reported to suppress autophagy by inhibiting cytosolic calcium elevation, which can induce autophagy (Hoyer-Hansen et al. 2007). Another Beclin 1 partner is UVRAG (UV irradiation resistance-associated gene) (Liang et al. 2006), which interacts via the coiled-coil region of Beclin 1 . UVRAG was shown to be a member of the class III PI3kinase complex and a positive regulator of autophagy. Most recently, a WD-40 domain-containing protein named Ambral, which was identified by a gene trap experiment, was shown to be a Beclin 1-interacting protein (Maria Fimia et al. 2007) and was shown to positively regulate Beclin 1-dependent autophagy. Ambral is primarily expressed in neural tissues and is indispensable for normal neural tube development. Therefore, mammalian Beclin 1 is likely to be regulated by its binding partners, which may not be present in yeast.

In contrast, it is known in yeast that Atg6/Vps30 functions in both autophagy and the Vps pathways by forming two distinct class III PI3-kinase complexes (Kihara et al. 2001). The type 1 complex is required for autophagy and comprises Atg6/Vps30, Vps34, Vps15, and Atg14, whereas the type 2 complex is required for the Vps pathway and contains Atg6/Vps30, Vps34, Vps15, and Vps38. The involvement of Atg6/Vps30/Beclin 1 in pathways other than autophagy remains controversial in other spe-

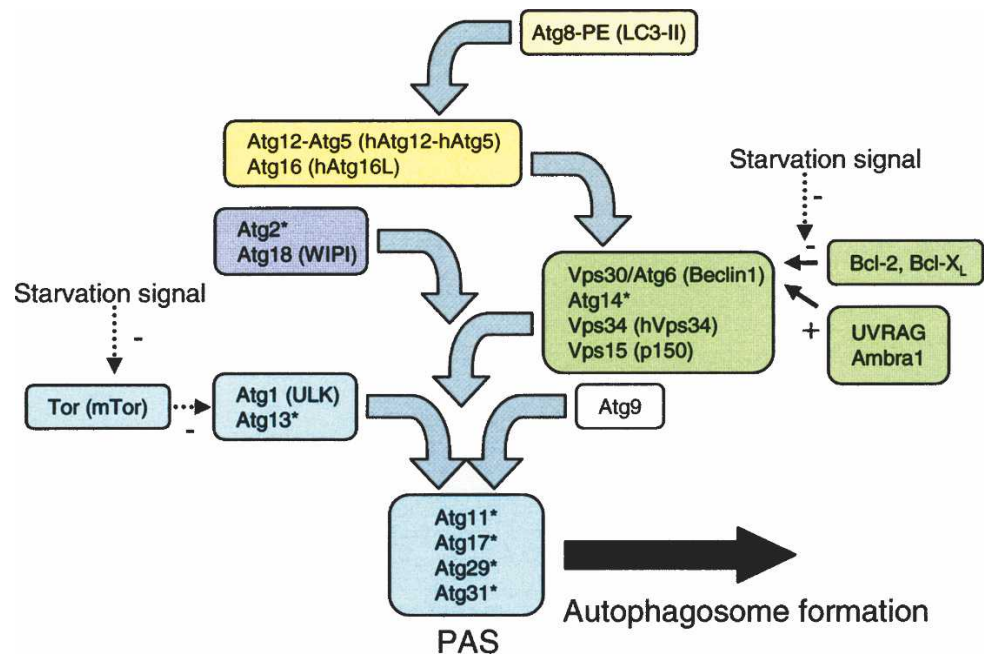

Figure 2. Interdependence of Atg proteins for PAS 1ocalization. This figure is based on the hierarchical classification analysis performed in yeast by Suzuki et al. (2007). Blue arrows indicate interdependence of Atg proteins for PAS targeting. For example, PAS-targeting of Atg5 is highly dependent on the class III PI3-kinase complex, but not on Atg8 or Atg2. Black arrows indicate positive and negative regulation. Some mammalian-specific proteins (Bcl-2, Bcl-X $\mathrm{L}_{\mathrm{L}}, \mathrm{UVRAG}$, and Ambra1) are listed, but PAS targeting has not been determined because a PAS-equivalent structure has not been identified in mammalian cells. Parentheses indicate mammalian nomenclature. Asterisks $\left(^{\star}\right)$ indicate factors that have been analyzed only in yeast 
cies (Takacs-Vellai et al. 2005; Zeng et al. 2006). Considering that Beclin 1 knockout mice die at about embryonic day 7.5 (Yue et al. 2003) whereas Atg5 and Atg7 knockout mice can survive until birth (Kuma et al. 2004; Komatsu et al. 2005), Beclin 1 likely has more complicated functions beyond autophagy. Characterization of its interacting proteins will facilitate our understanding of the role of Beclin 1 in autophagy and possibly other pathways.

Autophagosome membranes cannot recognize what they enclose, as most of their contents are not proximal to the autophagosomal membrane. Therefore, sequestration takes place primarily in a random manner. However, autophagosome membranes can recognize some proteins, and possibly organelles, at their surfaces. The best-studied example of such selective incorporation is the Cvt pathway (Klionsky and Ohsumi 1999; Klionsky 2005). This differs somewhat from canonical autophagy, as Cvt vesicles are much smaller than autophagosomes. However, as the membrane dynamics and molecular machinery of the Cvt pathway are quite similar to those of autophagy, the Cvt pathway may be thought of as selective autophagy of the vacuolar enzymes Ape1 and Ams1 (although these enzymes are not targeted for degradation). In this case, Atg19 functions as a cargo receptor for selective incorporation of these enzymes into $\mathrm{Cvt}$ vesicles (Klionsky 2005). Some Cvt-specific factors are also used for selective degradation of peroxisomes in $\mathrm{Pi}$ chia pastoris (Klionsky et al. 2003), suggesting the presence of machinery shared by selective autophagy. One way selective autophagy can be achieved is through the specific protein composition of the autophagosome membrane.

The compositions of the outer and inner autophagosomal membranes seem to be quite different. To date, only LC3, a mammalian homolog of Atg8, has been identified on the autophagosomal inner membrane (Kabeya et al. 2000). LC3 has been proposed to function as a receptor for a selective substrate, p62/SQSTM1 (Bjørkøy et al. 2005), which functions in a variety of signaling pathways (Wooten et al. 2006; Moscat et al. 2007) and is mutated in Paget disease patients (Laurin et al. 2002). Independent of these functions, p62/SQSTM1 binds to LC3 and is preferentially degraded by autophagy (Bjørkøy et al. 2005; Pankiv et al. 2007). p62/SQSTM1 markedly accumulates in autophagy-deficient cells (Wang et al. 2006; Nakai et al. 2007), confirming that it is selectively recognized and degraded by autophagy. Furthermore, since p62/SQSTM1 has a ubiquitin-binding domain, it has been proposed that ubiquitinated proteins and inclusion bodies can be recruited to the autophagosome membrane via p62/SQSTM1 (Bjørkøy et al. 2005; Pankiv et al. 2007). Although the precise mechanism is not known, preferential degradation by autophagy also has been demonstrated for Ald6 in yeast (Onodera and Ohsumi 2004), peroxisomes and catalase (Luiken et al. 1992; Iwata et al. 2006; Yu et al. 2006), mitochondria (Kim et al. 2007), and invading bacteria (Nakagawa et al. 2004; Ogawa et al. 2005). There should be various mechanisms underling selective autophagy, which remain to be revealed.

\section{Degradation}

In the next step, autophagosomes fuse with lysosomes (in metazoan cells) or vacuoles (in yeast and plant cells). The inner membrane of the autophagosome and the cytoplasm-derived materials contained in the autophagosome are then degraded by lysosomal/vacuolar hydrolases. One unique enzyme in this process is yeast Atg15/ Aut5/Cvt17, which is a putative lipase that is likely involved in the intravacuolar lysis of autophagic bodies (Epple et al. 2001; Teter et al. 2001).

These degrading structures are often called "autolysosomes" or "autophagolysosomes." However, since almost all lysosomes receive continuous flow from the endocytic pathway (Gordon and Seglen 1988), these autolysosomes should also contain heterophagic (non-self) materials. In addition, it has been proposed that autophagosomes fuse with endosomes to become amphisomes before fusion with lysosomes (Tooze et al. 1990; Berg et al. 1998). Fusion with endosomes is believed to provide nascent autophagosomes with machinery that is required for lysosome fusion.

The definition of autophagosomes, amphisomes, and autolysosomes is based on their function, not on morphology (Fig. 1). Therefore, it is not always easy to distinguish these structures by electron microscopy. In such cases, the term "autophagic vacuoles" may be used because it covers all autophagic structures (Fig. 1). Alternatively, morphological definitions such as initial autophagic vacuoles (AVi), intermediate autophagic vacuoles $(\mathrm{AVi} / \mathrm{d})$, and degrading autophagic vacuoles (AVd) can be used, which roughly represent autophagosomes, amphisomes, and autolysosomes. The average half-life of AVs appears to be $\sim 10 \mathrm{~min}$ (Pfeifer 1978; Schworer et al. 1981). One current problem is that this degradation step is rather difficult to measure, although some methods to monitor autophagy flux have been proposed (Tanida et al. 2005; Klionsky et al. 2007; Mizushima and Yoshimori 2007).

Reuse

Once macromolecules have been degraded in the lysosome/vacuole, monomeric units (e.g., amino acids) are exported to the cytosol for reuse. However, little is known about this step. Yeast Atg22, which was first identified as Aut4, a membrane protein required for the breakdown of autophagic bodies (Suriapranata et al. 2000), was later identified as a putative amino acid effluxer (Yang et al. 2006) that cooperates with other vacuolar permeases, such as Avt3 and Avt4. Although a mammalian counterpart of Atg22 has not been found, counterparts of Avt3 and Avt4 have been identified as SLC36A1/LYAAT-1 (lysosomal amino acid transporter1) (Sagné et al. 2001) and SLC36A4/LYAAT-2, respectively. The contribution of autophagy to reuse of other macromolecules such as carbohydrates and lipids is unknown.

\section{Function}

In this section, the physiological roles of autophagy are discussed based on the aforementioned processes (Fig. 3). 


\section{Utilization of degradation products}

Under normal conditions and during very short periods of starvation, maintenance of the amino acid pool seems to rely primarily on the ubiquitin-proteasome system rather than autophagy (Vabulas and Hartl 2005). However, during starvation that persists for several hours, necessary amino acids are produced by autophagy, which is up-regulated as an adaptive response. Indeed, both intracellular and extracellular amino acid levels decrease in autophagy-deficient yeast cells (Onodera and Ohsumi 2005) and mice (Kuma et al. 2004) when they are subjected to starvation. Although induction of autophagy is critical for survival of starvation, it is not fully understood how the generated amino acids are used. At least three pathways are likely to exist. First, in animals, carbohydrate stores (i.e., glycogen) are consumed within $1 \mathrm{~d}$ of starvation. Thereafter, glucose is supplied through gluconeogenesis in the liver; this process uses lactate and amino acids. In the well-described glucose-alanine cycle, alanine is secreted from peripheral tissues, including muscle, and is delivered to the liver to be converted to glucose during starvation. Autophagy may be a major contributor to this cycle.

Second, amino acids can be used as an energy source through the tricarboxylic acid (TCA) cycle. It is generally believed that both glucose and amino acids are important for energy homeostasis and cell proliferation (Newsholme et al. 1985). Recent studies have suggested that energy can be produced through autophagy. One study demonstrated that autophagy could support viability of an IL-3-dependent hematopoietic cell line (established from apoptosis-deficient mice) even after IL-3 withdrawal. However, when autophagy was also suppressed, cell viability could be restored by addition of methylpyruvate, which is cell permeable and can serve as a substrate of the TCA cycle (Lum et al. 2005a). Another recent study demonstrated that autophagy-defective embryoid body cells (differentiated from embryonic stem cells) undergoing apoptosis fail to expose phosphatidylserine at the cell surface due to low levels of cellular ATP, which can be overcome by addition of methylpyruvate (Qu et al. 2007). Finally, AMPK is activated in the hearts of starved $\mathrm{Atg} 5^{-/-}$mice, suggesting that autophagy also regulates energy status in vivo (Kuma et al. 2004).
Third, amino acids produced by autophagy can be used to synthesize proteins, which are important for adaptation to starvation environments. Yeast cells decrease bulk protein synthesis during starvation, but the reduction is much more severe in autophagy-defective mutant cells (Onodera and Ohsumi 2005). In addition, up-regulation of several starvation-induced proteins, including argininosuccinate synthetase (Arg1), heat shock protein of $26 \mathrm{kDa}$ (Hsp26), Ape1, and carboxypeptidase Y (CPY), occurs only slightly in autophagy mutants during nitrogen starvation. Inefficient production of such adaptive proteins may be a primary cause of loss of viability during starvation in autophagy-deficient cells (Tsukada and Ohsumi 1993). More dynamic nutrient mobilization via autophagy appears to be observed in remodeling during development. It should be noted that most remodeling steps are related to nutrient starvation, which can facilitate autophagy. These processes include spore formation in yeast (Tsukada and Ohsumi 1993), multicellular development (fruiting body formation) of Dictyostelium discoideum (Otto et al. 2003), dauer formation of Caenorhabditis elegans (Melendez et al. 2003), and metamorphosis of fly pupae (Juhasz et al. 2003; Scott et al. 2004). Indeed, autophagy-defective mutants do not succeed in these remodeling processes, probably due to shortage of amino acids, which cannot be obtained from the environment during these periods.

These three usages are not mutually exclusive. Cells or organisms probably combine more than one function to survive adverse conditions (Tsukada and Ohsumi 1993; Otto et al. 2003; Kuma et al. 2004; Scott et al. 2004). In addition to nutrient limitation, it has been suggested that autophagy might be responsive to hypoxia: Autophagy is induced in a mouse cerebral ischemia-hypoxia model (Adhami et al. 2006) and in ischemic myocardium (Yan et al. 2005; Matsui et al. 2007). This might be mediated by HIF-1, a master regulator of the hypoxic response (Bohensky et al. 2007). Furthermore, autophagy occurs in an in vitro metabolic stress model (glucose free, $1 \%$ oxygen), as well as in the center of tumors where ischemic conditions exist until angiogenesis is established (Degenhardt et al. 2006). Such metabolic stress typically induces apoptosis, but apoptosis-defective cells can survive under hypoxic conditions. Since cell survival depends on autophagy, excess amino acid generation is

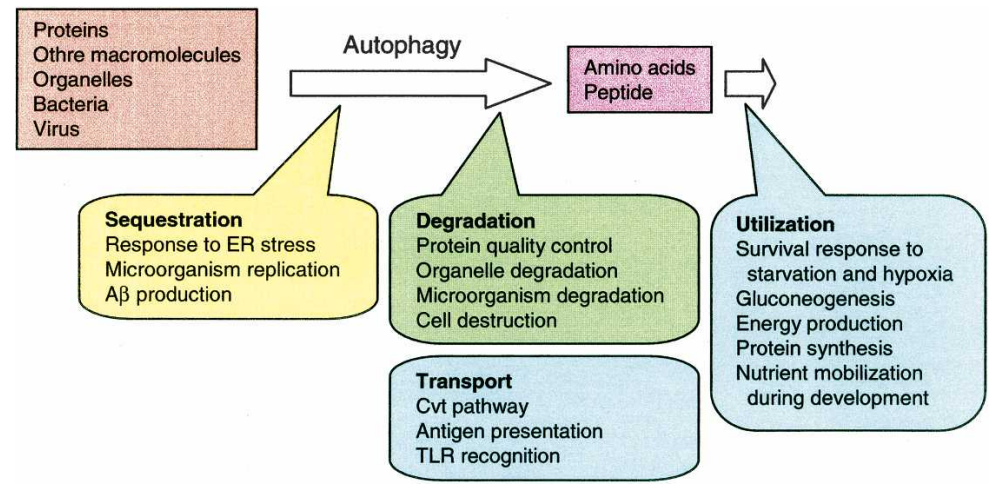

Figure 3. Functions of autophagy at each step. (See the text for details.) 
likely important under conditions of metabolic stress. If both apoptosis and autophagy are suppressed, cell survival is severely impaired. Intriguingly, the resulting necrotic cell death promotes tumorigenesis, which is probably mediated by the inflammatory response (Degenhardt et al. 2006). Thus, tumorigenesis may be a secondary effect of autophagy suppression in this context (further discussed below).

It should be emphasized that excess production of amino acids by autophagy is an acute response or emergency action. Therefore, induction of autophagy can support cell survival only for a short time. For example, during tumor growth, autophagy is activated at initial stages, but returns to basal levels after a blood supply is established (Degenhardt et al. 2006). In contrast, little is known about how useful autophagy is in overcoming chronic starvation.

\section{Elimination of macromolecules and organelles}

The second purpose of autophagy is the elimination of cytoplasmic contents. Although this role has been thought to be the specialty of the ubiquitin-proteasome system, many recent studies have shown that autophagy also participates in intracellular clearance or protein/organelle quality control. The most direct evidence is the accumulation of abnormal proteins and organelles in autophagy-deficient hepatocytes, neurons, and cardiomyocytes even in the absence of any disease-associated mutant protein (Komatsu et al. 2005, 2006; Hara et al. 2006; Nakai et al. 2007). Soluble ubiquitinated proteins, ubiquitin-positive inclusion bodies, and deformed organelles accumulate in these cells. Since induced autophagy is not observed in the brain during starvation, low levels of basal autophagy are likely sufficient for quality control.

Some types of induced autophagy are aimed at the elimination of excess or unneeded organelles. For example, peroxisomes induced by metabolic demand are selectively degraded primarily by microautophagy (Sakai et al. 1998) and macroautophagy (Iwata et al. 2006) in yeast and mammals, respectively, when they are no longer needed. Similarly, damaged mitochondria seem to be selectively eliminated by macroautophagy, while mitophagy occurs nonselectively under starvation conditions (Kim et al. 2007).

The elimination of cytoplasmic contents by autophagy is so important that defects cause various cellular malfunctions. Two possible outcomes of autophagy defects, neurodegeneration and tumorigenesis, are discussed further. The accumulation of autophagic vacuoles has been observed in many human neurodegenerative diseases, including Alzheimer's disease (Okamoto et al. 1991; Cataldo et al. 1996), polyglutamine (CAG) repeat diseases (Petersen et al. 2001; Ravikumar et al. 2002), and Parkinson's disease (Anglade et al. 1997). It remains largely unknown whether these represent up-regulation of autophagy or blockage of autophagic flux. Since neural tissue-specific knockout of autophagy genes causes neurodegenerative disease, and there are many reports showing that degradation of various disease-associated mu- tant proteins largely depends on autophagy (Rubinsztein 2006; Martinez-Vicente and Cuervo 2007), one would expect up-regulation of autophagic activity to be a useful therapeutic strategy for treatment of such disorders. Indeed, rapamycin and its analog CCI-779, which induce autophagy by inhibiting TOR, attenuate symptoms in fly and mouse Huntington disease models (Ravikumar et al. 2004). Furthermore, the autophagy-enhancing SMERs, which function independently of mTOR suppression, accelerate the clearance of mutant huntingtin and $\alpha$-synuclein and protect against neurodegeneration in a fly Huntington disease model (Sarkar et al. 2007). Whether abnormal proteins and inclusion bodies are selectively degraded by autophagy in these cases remains unknown; the random degradation of cytoplasmic contents may fully account for the effects of these autophagy inducers. However, as discussed above, p62-mediated recognition of ubiquitinated proteins and inclusion bodies was proposed (Bjørkøy et al. 2005; Pankiv et al. 2007). p62 gene-targeting experiments should further clarify the contribution of this type of selective autophagy.

Another possible outcome of defects in autophagic degradation is tumorigenesis. Although autophagy may be a survival mechanism for tumor cells (Lum et al. 2005a; Degenhardt et al. 2006; Amaravadi et al. 2007; Karantza-Wadsworth et al. 2007; Mathew et al. 2007), there are many reports that autophagy may act as a tumor suppressor (Hippert et al. 2006; Jin and White 2007; Levine 2007). Monoallelic deletions of Beclin 1 are frequently observed in human breast, ovarian, and prostate cancers (Liang et al. 1999). In addition, Beclin $1^{+/-}$mice consistently develop spontaneous malignancies (Qu et al. 2003; Yue et al. 2003). Allelic loss of beclin1 in immortal kidney and mammary epithelial cells promotes tumorigenesis (Karantza-Wadsworth et al. 2007; Mathew et al. 2007). Like Beclin 1, UVRAG is mutated in human cancers (Ionov et al. 2004; Liang et al. 2006). The expression of UVRAG suppresses anchorage-independent growth of HCT116 cells (human colon cancer cells with a UVRAG mutation), while a dominant-negative form of UVRAG promotes cell growth (Liang et al. 2006). Atg4C knockout mice show an increased susceptibility to carcinogen-induced fibrosarcomas (Marino et al. 2007). Finally, Ambral mutant mice show hyperproliferation of neural tissues, suggesting that loss of autophagy may lead to dysregulation of cell proliferation, although this phenotype is not observed in $A \operatorname{tg} 5^{-/-}$and $A \operatorname{tg} 7^{-/-}$mice. How autophagy protects against tumorigenesis is not fully understood. As discussed above, it was proposed that loss of autophagy causes necrotic cell death in apoptosis-deficient cells during metabolic stress; this might contribute to tumorigenesis via the inflammatory response (Degenhardt et al. 2006). However, it was also suggested that loss of autophagy in these cells has a cellautonomous effect on tumorigenesis; autophagy can limit genome damage (Karantza-Wadsworth et al. 2007; Mathew et al. 2007). High rates of gene amplification and aneuploidy were observed in Beclin $1^{+/-}$immortalized kidney epithelial cells. Atg $5^{-/-}$kidney epithelial cells 
also showed elevated induction of the DNA damage response during metabolic stress (Mathew et al. 2007). Furthermore, DNA damage and genomic instability were demonstrated in mammary epithelial cells in response to metabolic stress when both autophagy and apoptosis were suppressed (Karantza-Wadsworth et al. 2007). This genome damage and genetic instability promoted by defective autophagy may drive tumor progression by elevating the mutation rate. It may be that autophagy prevents the accumulation of abnormal proteins and organelles that are harmful to genomic stability; for example, as described above, damaged mitochondria can be selectively degraded by autophagy (Kim et al. 2007). Consistent with this, mitochondria with abnormal shape are found in Atg7-deficient hepatocytes (Komatsu et al. 2006). Even in yeast, autophagy was found to be important for maintaining mitochondrial function (Zhang et al. 2007). Importantly, ROS accumulate in autophagydefective yeast mutants when they are cultured in nonfermentable medium. Autophagy-defective plants also show increased oxidative stress under normal conditions (Xiong et al. 2007a). These ROS may promote DNA damage and ultimately tumorigenesis.

Elimination by autophagy is directed not only at cellular self-components, but also intracellular pathogens. Various pathogenic bacteria, such as Streptococcus pyogenes (Nakagawa et al. 2004) and Shigella flexneri (icsB mutant) (Ogawa et al. 2005), are sequestered by large autophagosomes or autophagosome-like structures and degraded following fusion with lysosomes. Another well-known pathogen persisting inside phagocytes is Mycobacterium tuberculosis. These bacteria inhibit phagosome maturation and survive in premature phagosomes. However, when autophagy is stimulated by starvation, rapamycin, or IFN- $\gamma$, mycobacterial phagosomes are enclosed, delivered to lysosomes, and acidified, which results in microbacterial death /Gutierrez et al. 2004). IFN- $\gamma$-induced autophagy in mouse cells requires a downstream effector, Irgm1 (LRG-47), which is an immunity-related guanosine triphosphatase (IRG) (Singh et al. 2006). In contrast to mouse cells, human IRGM is not induced by IFN- $\gamma$, but it was suggested that constitutive expression of IRGM could mediate autophagy in human macrophages (Singh et al. 2006). Recently, genome-wide association studies showed that both Atg16L1 and IRGM are susceptibility genes for Crohn's disease, an inflammatory bowel disorder (Hampe et al. 2007; Parkes et al. 2007; Rioux et al. 2007). Atg16L is one of two Atg16 homologs and interacts with the Atg12-Atg5 conjugate that is essential for autophagosome formation (Mizushima et al. 2003). Therefore, autophagy-mediated bacterial elimination might be important to prevent Crohn's disease.

It is also possible that excessive degradation by autophagy causes cell death. However, there is almost no evidence supporting this speculation under physiological or pathological conditions (Edinger and Thompson 2004; Debnath et al. 2005; Kroemer et al. 2005). During development, autophagy occurs in dying cells in various embryonic tissues (Levine and Klionsky 2004; Mizushima
2005). However, such autophagy can be interpreted as a nutrient mobilization system. It remains unknown whether these cells would survive if autophagy were blocked.

\section{Transportation from the cytoplasm to the lysosomel endosome}

At times, autophagy can be simply used as a pathway from the cytosol to lysosomes or vacuoles. The clearest example is the Cvt pathway in yeast. The vacuolar enzymes, Ape1 and Ams1, are synthesized without signal sequences and are cytosolic. They are delivered to the vacuole, where they function, by the autophagy-related Cvt pathway (Klionsky 2005). This is apparently a biosynthetic rather than a degradation pathway.

Autophagy is also used to present endogenous antigens on major histocompatibility complex (MHC) class II molecules, which are recognized by $\mathrm{CD} 4^{+} \mathrm{T}$ cells. In the case of MHC class I antigen presentation, the proteasome degrades endogenous antigens into peptides, which are then delivered to the ER lumen via the transporter associated with antigen processing (TAP). MHC class I molecules load these peptides and move to the cell surface to be recognized by $\mathrm{CD} 8^{+} \mathrm{T}$ cells. In contrast, the antigen-binding site of MHC class II molecules is blocked by the invariant chain until they reach the MHC class II loading compartment (MIIC), which is related to the lysosome. Therefore, endogenous peptides cannot bind MHC class II in the ER, allowing exogenous peptides to efficiently bind MHC class II following endocytosis. Nonetheless, $\sim 20 \%$ of peptides bound to MHC class II seem to be derived from cytosolic and nuclear proteins (Schmid and Münz 2007). Recent evidence suggests that autophagy (both macroautophagy and CMA) accounts for the delivery of these peptides (Schmid and Münz 2007). Furthermore, it was shown that influenza antigen fused to LC3 was preferentially incorporated into autophagosomes and very efficiently presented on MHC class II molecules (Schmid et al. 2007). This study demonstrates not only that this pathway is physiologically relevant but also that it might be applied to vaccine development.

The autophagy pathway is also used by plasmacytoid dendritic cells to recognize viral single-stranded RNA (ssRNA). Toll-like receptors (TLRs) are key molecules in innate immunity, which recognize various molecules derived from microbes. Some TLRs are present on the plasma membrane, while others localize to endosomes (TLR3, TLR7, TLR8, and TLR9). Among these, TLR7 recognizes viral ssRNA in endosomes and triggers immune responses, such as induction of inflammatory cytokines (Kawai and Akira 2006). However, it was recently demonstrated that cytosolic replication intermediates are also recognized by TLR7 following transportation to endosomes/lysosomes via autophagy, leading to interferon- $\alpha$ secretion by plasmacytoid dendritic cells (Lee et al. 2007). Autophagy is therefore a rather common pathway from the cytosol to lysosomes, in pathways other than degradation. 


\section{Sequestration/packing}

In some cases, sequestration in autophagic membranes, even without degradation, seems to be important to exert special functions. Autophagy can be induced by several stresses, including ER stress. Although there are likely to be some exceptions (Ding et al. 2007), ER stressinduced autophagy is basically protective against cell death in both yeast and mammals (Bernales et al. 2006; Ogata et al. 2006; Yorimitsu et al. 2006; Ding et al. 2007; Kouroku et al. 2007). How autophagy protects cells during ER stress is not exactly known, but it was suggested that sequestration of ER into autophagosomes might be sufficient to relieve ER stress (Bernales et al. 2006). When yeast cells are treated with ER stress-inducing agents such as DTT or tunicamycin, ER-containing autophagosomes (ERAs) appear in the cytoplasm. Surprisingly, these ERAs do not fuse with vacuoles (Bernales et al. 2006). Nonetheless, autophagy mutants show growth defects under severe ER stress conditions. Furthermore, vacuolar proteases are not required for this protective effect, confirming that ER sequestration, rather than degradation, is important in the response to ER stress. It is possible that stressed ER is segregated into ERAs so that it does not disseminate cytotoxic signals. Whether this is also the case in mammalian cells remains unknown.

As discussed above, autophagy is now recognized as part of the innate immune response to intracellular microorganisms. However, some pathogenic organisms are able to subvert autophagy for replication. Legionella pneumophila (Amer and Swanson 2005), Coxiella burnetti (Beron et al. 2002), Brucella abortus (Pizarro-Cerda et al. 1998), and Porphyromonas gingivalis (Dorn et al. 2001) have been suggested to enter the autophagic pathway. It is proposed that phagosomes containing these pathogens fuse with autophagosomes to generate protected vacuoles. These bacteria benefit from autophagy rather than being eliminated, because inhibition of autophagy reduces their survival. Although the precise mechanisms are unknown, these pathogens likely establish intracellular niches for survival and replication in autophagic (or related) vacuoles. This type of strategy is called the "pregnant pause" for survival (Swanson and Fernandez-Moreira 2002).

Similarly, while autophagy acts as a defense mechanism against some viruses (Tallóczy et al. 2002; Liu et al. 2005), others subvert the autophagic pathway for replication (Kirkegaard et al. 2004). Mouse hepatitis virus (MHV) induces the generation of intracellular doublemembraned vesicles, in which the virus replicates. These vesicles contain LC3, suggesting autophagosomal origin (Prentice et al. 2004). Unexpectedly, suppression of autophagy by Atg5 gene disruption in embryonic stem cells resulted in decreased MHV replication. Poliovirus, a picornavirus, also uses the autophagic machinery to induce double-membraned vesicles for replication (Jackson et al. 2005). Indeed, stimulation of autophagy increased virus yield. These reports suggest that autophagic structures provide membrane niches for the replication of certain viruses. However, conflicting observa- tions were recently reported. MHV replication seems not to require autophagy in macrophages and fibroblasts (Zhao et al. 2007), and vaccinia virus, which also induces cytoplasmic double-membraned structures for replication, does not require the autophagic machinery (Zhang et al. 2006). Furthermore, replication of human rhinovirus 2, another type of picornavirus, does not depend on autophagy (Brabec-Zaruba et al. 2007). Therefore, the concept of autophagy subversion by viruses may not be generalized.

As discussed above, the involvement of autophagy in pathogenesis has been suggested in the context of neurodegenerative disease. Autophagy likely has a beneficial role in the clearance of misfolded or other harmful proteins. However, if autophagic degradation is not rapid enough, sequestration of cytoplasm might rather have an adverse effect. It was proposed that autophagosome maturation into autolysosomes is impaired in Alzheimer's disease brains (Yu et al. 2005). The incompletely degraded autophagic vacuoles contain both amyloid precursor protein and $\gamma$-secretase complex, leading to the processing of APP into toxic $A \beta$ peptides. Thus, rapid and complete degradation of sequestered materials into amino acids may be important in neural cells.

\section{Concluding remarks}

In comparison with the ubiquitin-proteasome system, which involves $>1000$ genes in mammals, autophagy seems quite simple. However, as discussed in this review, autophagy should be viewed based on its elementary processes. Each step can have a variety of physiological roles, and despite efforts to assign known functions to individual steps, many proposed functions remain to be assigned. For example, autophagy was shown to be important for T-cell survival and proliferation (Pua et al. 2007), but it is unknown which function is important. Likewise, autophagy is suggested to be a protective response in cardiomyocytes during hemodynamic stress, but the mechanisms remain to be elucidated (Nakai et al. 2007). In some cases, more than one role of autophagy appears to be involved. For example, although autophagy is generally considered to be a tumor-suppressive process (Hippert et al. 2006; Levine 2007), the relationship between autophagy and cancer is complicated, in part because different steps of autophagy have different roles in tumor generation and tumor survival. A more quantitative view will be required to further understand the net role of autophagy in vivo. Finally, our knowledge of autophagy now seems to be ready for therapeutic application. Indeed, small molecules that can regulate autophagy seem to have great potential to modulate the clinical course of neurodegenerative diseases (Sarkar et al. 2007). In addition, pharmacologic inhibition of autophagy was reported to promote chemotherapeutic response in a mouse model for lymphoma (Amaravadi et al. 2007). More connections between autophagy and disease will likely be demonstrated in the very near future. 


\section{Acknowledgments}

This work was supported in part by Grants-in-Aid for Scientific Research from the Ministry of Education, Culture, Sports, Science and Technology of Japan. I also thank the Kato Memorial Bioscience Foundation and the Toray Science Foundation for financial support.

\section{References}

Adhami, F., Liao, G., Morozov, Y.M., Schloemer, A., Schmithorst, V.J., Lorenz, J.N., Dunn, R.S., Vorhees, C.V., WillsKarp, M., Degen, J.L., et al. 2006. Cerebral ischemia-hypoxia induces intravascular coagulation and autophagy. Am. J. Pathol. 169: 566-583.

Amaravadi, R.K., Yu, D., Lum, J.J., Bui, T., Christophorou, M.A., Evan, G.I., Thomas-Tikhonenko, A., and Thompson, C.B. 2007. Autophagy inhibition enhances therapy-induced apoptosis in a Myc-induced model of lymphoma. J. Clin. Invest. 117: 326-336.

Amer, A.O. and Swanson, M.S. 2005. Autophagy is an immediate macrophage response to Legionella pneumophila. Cell. Microbiol. 7: 765-778.

Anglade, P., Vyas, S., Javoy-Agid, F., Herrero, M.T., Michel, P.P., Marquez, J., Mouatt-Prigent, A., Ruberg, M., Hirsch, E.C., and Agid, Y. 1997. Apoptosis and autophagy in nigral neurons of patients with Parkinson's disease. Histol. Histopathol. 12: 25-31.

Berg, T.O., Fengsrud, M., Stromhaug, P.E., Berg, T., and Seglen, P.O. 1998. Isolation and characterization of rat liver amphisomes. Evidence for fusion of autophagosomes with both early and late endosomes. J. Biol. Chem. 273: 21883-21892.

Bernales, S., McDonald, K.L., and Walter, P. 2006. Autophagy counterbalances endoplasmic reticulum expansion during the unfolded protein response. PLOS Biol. 4: e423. doi: 10.1371/journal.pbio.0040423.

Beron, W., Gutierrez, M.G., Rabinovitch, M., and Colombo, M.I. 2002. Coxiella burnetii localizes in a Rab7-labeled compartment with autophagic characteristics. Infect. Immun. 70: 5816-5821.

Bjørkøy, G., Lamark, T., Brech, A., Outzen, H., Perander, M., Øvervatn, A., Stenmark, H., and Johansen, T. 2005. p62/ SQSTM1 forms protein aggregates degraded by autophagy and has a protective effect on huntingtin-induced cell death. J. Cell Biol. 171: 603-614.

Bohensky, J., Shapiro, I.M., Leshinsky, S., Terkhorn, S.P., Adams, C.S., and Srinivas, V. 2007. HIF-1 regulation of chondrocyte apoptosis: Induction of the autophagic pathway. Autophagy 3: 207-214.

Brabec-Zaruba, M., Berka, U., Blaas, D., and Fuchs, R. 2007. Induction of autophagy does not affect human Rhinovirus 2 production. J. Virol. 81: 10815-10817.

Byfield, M.P., Murray, J.T., and Backer, J.M. 2005. hVps34 is a nutrient-regulated lipid kinase required for activation of $\mathrm{p} 70$ S6 kinase. J. Biol. Chem. 280: 33076-33082.

Cataldo, A.M., Hamilton, D.J., Barnett, J.L., Paskevich, P.A., and Nixon, R.A. 1996. Properties of the endosomal-lysosomal system in the human central nervous system: Disturbances mark most neurons in populations at risk to degenerate in Alzheimer's disease. J. Neurosci. 16: 186-199.

Codogno, P. and Meijer, A.J. 2005. Autophagy and signaling: Their role in cell survival and cell death. Cell Death Differ. 12 (Suppl. 2): 1509-1518.

Crighton, D., Wilkinson, S., O'Prey, J., Syed, N., Smith, P., Harrison, P.R., Gasco, M., Garrone, O., Crook, T., and Ryan, K.M. 2006. DRAM, a p53-induced modulator of autophagy, is critical for apoptosis. Cell 126: 121-134.

Criollo, A., Maiuri, M.C., Tasdemir, E., Vitale, I., Fiebig, A.A., Andrews, D., Molgo, J., Diaz, J., Lavandero, S., Harper, F., et al. 2007. Regulation of autophagy by the inositol trisphosphate receptor. Cell Death Differ. 14: 1029-1039.

Cuervo, A.M. 2004. Autophagy: In sickness and in health. Trends Cell Biol. 14: 70-77.

Daido, S., Kanzawa, T., Yamamoto, A., Takeuchi, H., Kondo, Y., and Kondo, S. 2004. Pivotal role of the cell death factor BNIP3 in ceramide-induced autophagic cell death in malignant glioma cells. Cancer Res. 64: 4286-4293.

Debnath, J., Baehrecke, E.H., and Kroemer, G. 2005. Does autophagy contribute to cell death? Autophagy 1: 66-74.

Degenhardt, K., Mathew, R., Beaudoin, B., Bray, K., Anderson, D., Chen, G., Mukherjee, C., Shi, Y., Gelinas, C., Fan, Y., et al. 2006. Autophagy promotes tumor cell survival and restricts necrosis, inflammation, and tumorigenesis. Cancer Cell 10: 51-64.

Demarchi, F., Bertoli, C., Copetti, T., Tanida, I., Brancolini, C., Eskelinen, E.-L., and Schneider, C. 2006. Calpain is required for macroautophagy in mammalian cells. J. Cell Biol. 175: 595-605.

de Waal, E.J., Vreeling-Sindelarova, H., Schellens, J.P., Houtkooper, J.M., and James, J. 1986. Quantitative changes in the lysosomal vacuolar system of rat hepatocytes during shortterm starvation. A morphometric analysis with special reference to macro- and microautophagy. Cell Tissue Res. 243: 641-648.

Ding, W.X., Ni, H.M., Gao, W., Hou, Y.F., Melan, M.A., Chen, X., Stolz, D.B., Shao, Z.M., and Yin, X.M. 2007. Differential effects of endoplasmic reticulum stress-induced autophagy on cell survival. J. Biol. Chem. 282: 4702-4710.

Djavaheri-Mergny, M., Amelotti, M., Mathieu, J., Besancon, F., Bauvy, C., Souquere, S., Pierron, G., and Codogno, P. 2006. NF- $\kappa$ B activation represses tumor necrosis factor- $\alpha$-induced autophagy. J. Biol. Chem. 281: 30373-30382.

Dorn, B.R., Dunn Jr., W.A., and Progulske-Fox, A. 2001. Porphyromonas gingivalis traffics to autophagosomes in human coronary artery endothelial cells. Infect. Immun. 69: 56985708.

Edinger, A.L. and Thompson, C.B. 2004. Death by design: Apoptosis, necrosis and autophagy. Curr. Opin. Cell Biol. 16: 663-669.

Epple, U.D., Suriapranata, I., Eskelinen, E.-L., and Thumm, M. 2001. Aut5/Cvt17p, a putative lipase essential for disintegration of autophagic bodies inside the vacuole. J. Bacteriol. 183: 5942-5955.

Gordon, P.B. and Seglen, P.O. 1988. Prelysosomal convergence of autophagic and endocytic pathways. Biochem. Biophys. Res. Commun. 151: 40-47.

Gutierrez, M.G., Master, S.S., Singh, S.B., Taylor, G.A., Colombo, M.I., and Deretic, V. 2004. Autophagy is a defense mechanism inhibiting BCG and Mycobacterium tuberculosis survival in infected macrophages. Cell 119: 753-766.

Hampe, J., Franke, A., Rosenstiel, P., Till, A., Teuber, M., Huse, K., Albrecht, M., Mayr, G., De La Vega, F.M., Briggs, J., et al. 2007. A genome-wide association scan of nonsynonymous SNPs identifies a susceptibility variant for Crohn disease in ATG16L1. Nat. Genet. 39: 207-211.

Hara, T., Nakamura, K., Matsui, M., Yamamoto, A., Nakahara, Y., Suzuki-Migishima, R., Yokoyama, M., Mishima, K., Saito, I., Okano, H., et al. 2006. Suppression of basal autophagy in neural cells causes neurodegenerative disease in mice. Nature 441: 885-889.

Hippert, M.M., O'Toole, P.S., and Thorburn, A. 2006. Autophagy in cancer: Good, bad, or both? Cancer Res. 66: 9349-9351. 
Hoyer-Hansen, M., Bastholm, L., Szyniarowski, P., Campanella, M., Szabadkai, G., Farkas, T., Bianchi, K., Fehrenbacher, N., Elling, F., Rizzuto, R., et al. 2007. Control of macroautophagy by calcium, calmodulin-dependent kinase kinase- $\beta$, and Bcl-2. Mol. Cell 25: 193-205.

Ionov, Y., Nowak, N., Perucho, M., Markowitz, S., and Cowell, J.K. 2004. Manipulation of nonsense mediated decay identifies gene mutations in colon cancer cells with microsatellite instability. Oncogene 23: 639-645.

Iwata, J., Ezaki, J., Komatsu, M., Yokota, S., Ueno, T., Tanida, I., Chiba, T., Tanaka, K., and Kominami, E. 2006. Excess peroxisomes are degraded by autophagic machinery in mammals. J. Biol. Chem. 281: 4035-4041.

Jackson, W.T., Giddings Jr., T.H., Taylor, M.P., Mulinyawe, S., Rabinovitch, M., Kopito, R.R., and Kirkegaard, K. 2005. Subversion of cellular autophagosomal machinery by RNA viruses. PLoS Biol. 3: e156. doi: 10.1371/journal.pbio.0030156.

Jin, S. and White, E. 2007. Role of autophagy in cancer: Management of metabolic stress. Autophagy 3: 28-31.

Juhasz, G., Csikos, G., Sinka, R., Erdelyi, M., and Sass, M. 2003. The Drosophila homolog of Aut1 is essential for autophagy and development. FEBS Lett. 543: 154-158.

Kabeya, Y., Mizushima, N., Ueno, T., Yamamoto, A., Kirisako, T., Noda, T., Kominami, E., Ohsumi, Y., and Yoshimori, T. 2000. LC3, a mammalian homologue of yeast Apg8p, is localized in autophagosome membranes after processing. EMBO J. 19: 5720-5728.

Kabeya, Y., Kawamata, T., Suzuki, K., and Ohsumi, Y. 2007. Cis1/Atg31 is required for autophagosome formation in Saccharomyces cerevisiae. Biochem. Biophys. Res. Commun. 356: 405-410.

Kanazawa, T., Taneike, I., Akaishi, R., Yoshizawa, F., Furuya, N., Fujimura, S., and Kadowaki, M. 2004. Amino acids and insulin control autophagic proteolysis through different signaling pathways in relation to mTOR in isolated rat hepatocytes. J. Biol. Chem. 279: 8452-8459.

Karantza-Wadsworth, V., Patel, S., Kravchuk, O., Chen, G., Mathew, R., Jin, S., and White, E. 2007. Autophagy mitigates metabolic stress and genome damage in mammary tumorigenesis. Genes \& Dev. 21: 1621-1635.

Kawai, T. and Akira, S. 2006. TLR signaling. Cell Death Differ. 13: $816-825$

Kawamata, T., Kamada, Y., Suzuki, K., Kuboshima, N., Akimatsu, H., Ota, S., Ohsumi, M., and Ohsumi, Y. 2005. Characterization of a novel autophagy-specific gene, ATG29. Biochem. Biophys. Res. Commun. 338: 1884-1889.

Kihara, A., Noda, T., Ishihara, N., and Ohsumi, Y. 2001. Two distinct Vps34 phosphatidylinositol 3-kinase complexes function in autophagy and carboxypeptidase $\mathrm{Y}$ sorting in Saccharomyces cerevisiae. J. Cell Biol. 152: 519-530.

Kim, J., Huang, W.-P., and Klionsky, D.J. 2001. Membrane recruitment of Aut7p in the autophagy and cytoplasm to vacuole targeting pathways requires Aut $1 \mathrm{p}$, Aut $2 \mathrm{p}$, and autophagy conjugation complex. J. Cell Biol. 152: 51-64.

Kim, I., Rodriguez-Enriquez, S., and Lemasters, J.J. 2007. Selective degradation of mitochondria by mitophagy. Arch. Biochem. Biophys. 462: 245-253.

Kirkegaard, K., Taylor, M.P., and Jackson, W.T. 2004. Cellular autophagy: Surrender, avoidance and subversion by microorganisms. Nat. Rev. Microbiol. 2: 301-314.

Klionsky, D.J. 2005. The molecular machinery of autophagy: Unanswered questions. J. Cell Sci. 118: 7-18.

Klionsky, D.J. 2007. Autophagy: From phenomenology to molecular understanding in less than a decade. Nat. Rev. Mol. Cell Biol. doi: 10.1038/nrm2245.

Klionsky, D.J. and Ohsumi, Y. 1999. Vacuolar import of pro- teins and organelles from the cytoplasm. Annu. Rev. Cell Dev. Biol. 15: 1-32.

Klionsky, D.J., Cregg, J.M., Dunn Jr., W.A., Emr, S.D., Sakai, Y., Sandoval, I.V., Sibirny, A., Subramani, S., Thumm, M., Veenhuis, M., et al. 2003. A unified nomenclature for yeast autophagy-related genes. Dev. Cell 5: 539-545.

Klionsky, D.J., Cuervo, A.M., and Seglen, P.O. 2007. Methods for monitoring autophagy from yeast to human. Autophagy 3: 181-206.

Komatsu, M., Waguri, S., Ueno, T., Iwata, J., Murata, S., Tanida, I., Ezaki, J., Mizushima, N., Ohsumi, Y., Uchiyama, Y., et al. 2005. Impairment of starvation-induced and constitutive autophagy in Atg7-deficient mice. J. Cell Biol. 169: 425-434.

Komatsu, M., Waguri, S., Chiba, T., Murata, S., Iwata, J.I., Tanida, I., Ueno, T., Koike, M., Uchiyama, Y., Kominami, E., et al. 2006. Loss of autophagy in the central nervous system causes neurodegeneration in mice. Nature 441: 880-884.

Kouroku, Y., Fujita, E., Tanida, I., Ueno, T., Isoai, A., Kumagai, H., Ogawa, S., Kaufman, R.J., Kominami, E., and Momoi, T. 2007. ER stress (PERK/eIF2 $\alpha$ phosphorylation) mediates the polyglutamine-induced LC3 conversion, an essential step for autophagy formation. Cell Death Differ. 14: 230-239.

Kroemer, G., El-Deiry, W.S., Golstein, P., Peter, M.E., Vaux, D., Vandenabeele, P., Zhivotovsky, B., Blagosklonny, M.V., Malorni, W., Knight, R.A., et al. 2005. Classification of cell death: Recommendations of the Nomenclature Committee on Cell Death. Cell Death Differ. 12 (Suppl. 2): 1463-1467.

Kuma, A., Hatano, M., Matsui, M., Yamamoto, A., Nakaya, H., Yoshimori, T., Ohsumi, Y., Tokuhisa, T., and Mizushima, N. 2004. The role of autophagy during the early neonatal starvation period. Nature 432: 1032-1036.

Laurin, N., Brown, J.P., Morissette, J., and Raymond, V. 2002. Recurrent mutation of the gene encoding sequestosome 1 (SQSTM1/p62) in Paget disease of bone. Am. J. Hum. Genet. 70: $1582-1588$.

Lee, H.K., Lund, J.M., Ramanathan, B., Mizushima, N., and Iwasaki, A. 2007. Autophagy-dependent viral recognition by plasmacytoid dendritic cells. Science 315: 1398-1401.

Levine, B. 2007. Cell biology: Autophagy and cancer. Nature 446: $745-747$.

Levine, B. and Klionsky, D.J. 2004. Development by self-digestion: Molecular mechanisms and biological functions of autophagy. Dev. Cell 6: 463-477.

Liang, X.H., Kleeman, L.K., Jiang, H.H., Gordon, G., Goldman, J.E., Berry, G., Herman, B., and Levine, B. 1998. Protection against fatal Sindbis virus encephalitis by Beclin, a novel Bcl-2-interacting protein. J. Virol. 72: 8586-8596.

Liang, X.H., Jackson, S., Seaman, M., Brown, K., Kempkes, B., Hibshoosh, H., and Levine, B. 1999. Induction of autophagy and inhibition of tumorigenesis by beclin 1. Nature 402: 672-676.

Liang, C., Feng, P., Ku, B., Dotan, I., Canaani, D., Oh, B.H., and Jung, J.U. 2006. Autophagic and tumour suppressor activity of a novel Beclin1-binding protein UVRAG. Nat. Cell Biol. 8: 688-699.

Liang, J., Shao, S.H., Xu, Z.X., Hennessy, B., Ding, Z., Larrea, M., Kondo, S., Dumont, D.J., Gutterman, J.U., Walker, C.L., et al. 2007. The energy sensing LKB1-AMPK pathway regulates p27(kip1) phosphorylation mediating the decision to enter autophagy or apoptosis. Nat. Cell Biol. 9: 218-224.

Liu, Y., Schiff, M., Czymmek, K., Talloczy, Z., Levine, B., and Dinesh-Kumar, S.P. 2005. Autophagy regulates programmed cell death during the plant innate immune response. Cell 121: $567-577$.

Luiken, J.J., van den Berg, M., Heikoop, J.C., and Meijer, A.J. 1992. Autophagic degradation of peroxisomes in isolated rat 
hepatocytes. FEBS Lett. 304: 93-97.

Lum, J.J., Bauer, D.E., Kong, M., Harris, M.H., Li, C., Lindsten, T., and Thompson, C.B. 2005a. Growth factor regulation of autophagy and cell survival in the absence of apoptosis. Cell 120: $237-248$.

Lum, J.J., Deberardinis, R.J., and Thompson, C.B. 2005b. Autophagy in metazoans: Cell survival in the land of plenty. Nat. Rev. Mol. Cell Biol. 6: 439-448.

Maiuri, M.C., Le Toumelin, G., Criollo, A., Rain, J.C., Gautier, F., Juin, P., Tasdemir, E., Pierron, G., Troulinaki, K., Tavernarakis, N., et al. 2007. Functional and physical interaction between Bcl-X(L) and a BH3-like domain in Beclin-1. EMBO J. 26: $2527-2539$.

Maria Fimia, G., Stoykova, A., Romagnoli, A., Giunta, L., Di Bartolomeo, S., Nardacci, R., Corazzari, M., Fuoco, C., Ucar, A., Schwartz, P., et al. 2007. Ambral regulates autophagy and development of the nervous system. Nature 447: 11211125.

Marino, G., Salvador-Montoliu, N., Fueyo, A., Knecht, E., Mizushima, N., and Lopez-Otin, C. 2007. Tissue-specific autophagy alterations and increased tumorigenesis in mice deficient in Atg4C/autophagin-3. J. Biol. Chem. 282: 1857318583.

Martinez-Vicente, M. and Cuervo, A.M. 2007. Autophagy and neurodegeneration: When the cleaning crew goes on strike. Lancet Neurol. 6: 352-361.

Mathew, R., Kongara, S., Beaudoin, B., Karp, C.M., Bray, K., Degenhardt, K., Chen, G., Jin, S., and White, E. 2007. Autophagy suppresses tumor progression by limiting chromosomal instability. Genes \& Dev. 21: 1367-1381.

Matsui, Y., Takagi, H., Qu, X., Abdellatif, M., Sakoda, H., Asano, T., Levine, B., and Sadoshima, J. 2007. Distinct roles of autophagy in the heart during ischemia and reperfusion: Roles of AMP-activated protein kinase and Beclin 1 in mediating autophagy. Circ. Res. 100: 914-922.

Melendez, A., Tallóczy, Z., Seaman, M., Eskelinen, E.-L., Hall, D.H., and Levine, B. 2003. Autophagy genes are essential for dauer development and life-span extension in C. elegans. Science 301: 1387-1391.

Meley, D., Bauvy, C., Houben-Weerts, J.H., Dubbelhuis, P.F., Helmond, M.T., Codogno, P., and Meijer, A.J. 2006. AMPactivated protein kinase and the regulation of autophagic proteolysis. J. Biol. Chem. 281: 34870-34879.

Mills, K.R., Reginato, M., Debnath, J., Queenan, B., and Brugge, J.S. 2004. Tumor necrosis factor-related apoptosis-inducing ligand (TRAIL) is required for induction of autophagy during lumen formation in vitro. Proc. Natl. Acad. Sci. 101: 34383443.

Mizushima, N. 2005. The pleiotropic role of autophagy: From protein metabolism to bactericide. Cell Death Differ. 12 (Suppl. 2): 1535-1541.

Mizushima, N. and Klionsky, D.J. 2007. Protein turnover via autophagy: Implications for metabolism. Annu. Rev. Nutr. 27: 19-40.

Mizushima, N. and Yoshimori, T. 2007. How to interpret LC3 immunoblotting. Autophagy 3: 542-545.

Mizushima, N., Kuma, A., Kobayashi, Y., Yamamoto, A., Matsubae, M., Takao, T., Natsume, T., Ohsumi, Y., and Yoshimori, T. 2003. Mouse Apg16L, a novel WD-repeat protein, targets to the autophagic isolation membrane with the Apg12-Apg5 conjugate. J. Cell Sci. 116: 1679-1688.

Mizushima, N., Yamamoto, A., Matsui, M., Yoshimori, T., and Ohsumi, Y. 2004. In vivo analysis of autophagy in response to nutrient starvation using transgenic mice expressing a fluorescent autophagosome marker. Mol. Biol. Cell 15: 1101-1111.
Mordier, S., Deval, C., Bechet, D., Tassa, A., and Ferrara, M. 2000. Leucine limitation induces autophagy and activation of lysosome-dependent proteolysis in $\mathrm{C} 2 \mathrm{C} 12$ myotubes through a mammalian target of rapamycin-independent signaling pathway. J. Biol. Chem. 275: 29900-29906.

Moriyasu, Y. and Ohsumi, Y. 1996. Autophagy in tobacco suspension-cultured cells in response to sucrose starvation. Plant Physiol. 111: 1233-1241.

Mortimore, G.E. and Pösö, A.R. 1987. Intracellular protein catabolism and its control during nutrient deprivation and supply. Annu. Rev. Nutr. 7: 539-564.

Mortimore, G.E., Hutson, N.J., and Surmacz, C.A. 1983. Quantitative correlation between proteolysis and macro- and microautophagy in mouse hepatocytes during starvation and refeeding. Proc. Natl. Acad. Sci. 80: 2179-2183.

Moscat, J., Diaz-Meco, M.T., and Wooten, M.W. 2007. Signal integration and diversification through the p62 scaffold protein. Trends Biochem. Sci. 32: 95-100.

Nakagawa, I., Amano, A., Mizushima, N., Yamamoto, A., Yamaguchi, H., Kamimoto, T., Nara, A., Funao, J., Nakata, M., Tsuda, K., et al. 2004. Autophagy defends cells against invading group A Streptococcus. Science 306: 1037-1040.

Nakai, A., Yamaguchi, O., Takeda, T., Higuchi, Y., Hikoso, S., Taniike, M., Omiya, S., Mizote, I., Matsumura, Y., Asahi, M., et al. 2007. The role of autophagy in cardiomyocytes in the basal state and in response to hemodynamic stress. Nat. Med. 13: 619-624.

Nakatogawa, H., Ichimura, Y., and Ohsumi, Y. 2007. Atg8, a ubiquitin-like protein required for autophagosome formation, mediates membrane tethering and hemifusion. Cell 130: $165-178$.

Newsholme, E.A., Crabtree, B., and Ardawi, M.S. 1985. Glutamine metabolism in lymphocytes: Its biochemical, physiological and clinical importance. Q. J. Exp. Physiol. 70: 473489.

Nobukuni, T., Joaquin, M., Roccio, M., Dann, S.G., Kim, S.Y., Gulati, P., Byfield, M.P., Backer, J.M., Natt, F., Bos, J.L., et al. 2005. Amino acids mediate $\mathrm{mTOR} /$ raptor signaling through activation of class 3 phosphatidylinositol $3 \mathrm{OH}$-kinase. Proc. Nat1. Acad. Sci. 102: 14238-14243.

Noda, T. and Ohsumi, Y. 1998. Tor, a phosphatidylinositol kinase homologue, controls autophagy in yeast. J. Biol. Chem. 273: 3963-3966.

Oberstein, A., Jeffrey, P.D., and Shi, Y. 2007. Crystal structure of the Bcl-XL-Beclin 1 peptide complex: Beclin 1 is a novel BH3-only protein. J. Biol. Chem. 282: 13123-13132.

Ogata, M., Hino, S., Saito, A., Morikawa, K., Kondo, S., Kanemoto, S., Murakami, T., Taniguchi, M., Tanii, I., Yoshinaga, K., et al. 2006. Autophagy is activated for cell survival after endoplasmic reticulum stress. Mol. Cell. Biol. 26: 92209231.

Ogawa, M., Yoshimori, T., Suzuki, T., Sagara, H., Mizushima, N., and Sasakawa, C. 2005. Escape of intracellular Shigella from autophagy. Science 307: 727-731.

Okamoto, K., Hirai, S., Iizuka, T., Yanagisawa, T., and Watanabe, M. 1991. Reexamination of granulovacuolar degeneration. Acta Neuropathol. (Berl.) 82: 340-345.

Onodera, J. and Ohsumi, Y. 2004. Ald6p is a preferred target for autophagy in yeast, Saccharomyces cerevisiae. I. Biol. Chem. 279: 16071-16076.

Onodera, J. and Ohsumi, Y. 2005. Autophagy is required for maintenance of amino acid levels and protein synthesis under nitrogen starvation. J. Biol. Chem. 280: 31582-31586.

Otto, G.P., Wu, M.Y., Kazgan, N., Anderson, O.R., and Kessin, R.H. 2003. Macroautophagy is required for multicellular development of the social amoeba Dictyostelium discoideum. 
J. Biol. Chem. 278: 17636-17645.

Palou, A., Remesar, X., Arola, L., Herrera, E., and Alemany, M. 1981. Metabolic effects of short term food deprivation in the rat. Horm. Metab. Res. 13: 326-330.

Pankiv, S., Hoyvarde Clausen, T., Lamark, T., Brech, A., Bruun, J.A., Outzen, H., Øvervatn, A., Bjørkøy, G., and Johansen, T 2007. p62/SQSTM1 binds directly to Atg8/LC3 to facilitate degradation of ubiquitinated protein aggregates by autophagy. J. Biol. Chem. 282: 24131-24145.

Parkes, M., Barrett, J.C., Prescott, N.J., Tremelling, M., Anderson, C.A., Fisher, S.A., Roberts, R.G., Nimmo, E.R., Cummings, F.R., Soars, D., et al. 2007. Sequence variants in the autophagy gene IRGM and multiple other replicating loci contribute to Crohn's disease susceptibility. Nat. Genet. 39: 830-832.

Pattingre, S., Tassa, A., Qu, X., Garuti, R., Liang, X.H., Mizushima, N., Packer, M., Schneider, M.D., and Levine, B. 2005. Bcl-2 antiapoptotic proteins inhibit Beclin 1-dependent autophagy. Cell 122: 927-939.

Petersen, A., Larsen, K.E., Behr, G.G., Romero, N., Przedborski, S., Brundin, P., and Sulzer, D. 2001. Expanded CAG repeats in exon 1 of the Huntington's disease gene stimulate dopamine-mediated striatal neuron autophagy and degeneration. Hum. Mol. Genet. 10: 1243-1254.

Pfeifer, U. 1978. Inhibition by insulin of the formation of autophagic vacuoles in rat liver. A morphometric approach to the kinetics of intracellular degradation by autophagy. J. Cell Biol. 78: 152-167.

Pizarro-Cerda, J., Moreno, E., Sanguedolce, V., Mege, J.L., and Gorvel, J.P. 1998. Virulent Brucella abortus prevents lysosome fusion and is distributed within autophagosome-like compartments. Infect. Immun. 66: 2387-2392.

Prentice, E., Jerome, W.G., Yoshimori, T., Mizushima, N., and Denison, M.R. 2004. Coronavirus replication complex formation utilizes components of cellular autophagy. J. Biol. Chem. 279: 10136-10141.

Pua, H.H., Dzhagalov, I., Chuck, M., Mizushima, N., and He, Y.W. 2007. A critical role for the autophagy gene Atg5 in T cell survival and proliferation. J. Exp. Med. 204: 25-31.

Pyo, J.O., Jang, M.H., Kwon, Y.K., Lee, H.J., Jun, J.I., Woo, H.N., Cho, D.H., Choi, B., Lee, H., Kim, J.H., et al. 2005. Essential Roles of Atg5 and FADD in autophagic cell death: Dissection of autophagic cell death into vacuole formation and cell death. J. Biol. Chem. 280: 20722-20729.

Qu, X., Yu, J., Bhagat, G., Furuya, N., Hibshoosh, H., Troxel, A., Rosen, J., Eskelinen, E.-L., Mizushima, N., Ohsumi, Y., et al. 2003. Promotion of tumorigenesis by heterozygous disruption of the beclin 1 autophagy gene. J. Clin. Invest. 112: $1809-1820$

Qu, X., Zou, Z., Sun, Q., Luby-Phelps, K., Cheng, P., Hogan, R.N., Gilpin, C., and Levine, B. 2007. Autophagy gene-dependent clearance of apoptotic cells during embryonic development. Cell 128: 931-946.

Ravikumar, B., Duden, R., and Rubinsztein, D.C. 2002. Aggregate-prone proteins with polyglutamine and polyalanine expansions are degraded by autophagy. Hum. Mol. Genet. 11: $1107-1117$

Ravikumar, B., Vacher, C., Berger, Z., Davies, J.E., Luo, S., Oroz, L.G., Scaravilli, F., Easton, D.F., Duden, R., O'Kane, C.J., et al. 2004. Inhibition of $\mathrm{mTOR}$ induces autophagy and reduces toxicity of polyglutamine expansions in fly and mouse models of Huntington disease. Nat. Genet. 36: 585-595.

Reef, S., Zalckvar, E., Shifman, O., Bialik, S., Sabanay, H., Oren, M., and Kimchi, A. 2006. A short mitochondrial form of p19ARF induces autophagy and caspase-independent cell death. Mol. Cell 22: 463-475.
Rioux, J.D., Xavier, R.J., Taylor, K.D., Silverberg, M.S., Goyette, P., Huett, A., Green, T., Kuballa, P., Barmada, M.M., Datta, L.W., et al. 2007. Genome-wide association study identifies new susceptibility loci for Crohn disease and implicates autophagy in disease pathogenesis. Nat. Genet. 39: 596-604.

Rubinsztein, D.C. 2006. The roles of intracellular protein-degradation pathways in neurodegeneration. Nature 443: 780786.

Rusten, T.E., Lindmo, K., Juhasz, G., Sass, M., Seglen, P.O., Brech, A., and Stenmark, H. 2004. Programmed autophagy in the Drosophila fat body is induced by ecdysone through regulation of the PI3K pathway. Dev. Cell 7: 179-192.

Sagné, C., Agulhon, C., Ravassard, P., Darmon, M., Hamon, M., El Mestikawy, S., Gasnier, B., and Giros, B. 2001. Identification and characterization of a lysosomal transporter for small neutral amino acids. Proc. Natl. Acad. Sci. 98: 72067211.

Sakai, Y., Koller, A., Rangell, L.K., Keller, G.A., and Subramani, S. 1998. Peroxisome degradation by microautophagy in $\mathrm{Pi}$ chia pastoris: Identification of specific steps and morphological intermediates. J. Cell Biol. 141: 625-636.

Sarkar, S., Floto, R.A., Berger, Z., Imarisio, S., Cordenier, A., Pasco, M., Cook, L.J., and Rubinsztein, D.C. 2005. Lithium induces autophagy by inhibiting inositol monophosphatase. I. Cell Biol. 170: 1101-1111.

Sarkar, S., Perlstein, E.O., Imarisio, S., Pineau, S., Cordenier, A., Maglathlin, R.L., Webster, J.A., Lewis, T.A., O'Kane, C.J., Schreiber, S.L., et al. 2007. Small molecules enhance autophagy and reduce toxicity in Huntington's disease models. Nat. Chem. Biol. 3: 331-338.

Scherz-Shouval, R., Shvets, E., Fass, E., Shorer, H., Gil, L., and Elazar, Z. 2007. Reactive oxygen species are essential for autophagy and specifically regulate the activity of Atg4. $E M B O$ J. 26: 1749-1760.

Schmid, D. and Münz, C. 2007. Innate and adaptive immunity through autophagy. Immunity 27: 11-21.

Schmid, D., Pypaert, M., and Münz, C. 2007. Antigen-loading compartments for major histocompatibility complex class II molecules continuously receive input from autophagosomes. Immunity 26: 79-92.

Schworer, C.M., Shiffer, K.A., and Mortimore, G.E. 1981. Quantitative relationship between autophagy and proteolysis during graded amino acid deprivation in perfused rat liver. $J$. Biol. Chem. 256: 7652-7658.

Scott, R.C., Schuldiner, O., and Neufeld, T.P. 2004. Role and regulation of starvation-induced autophagy in the Drosophila fat body. Dev. Cell 7: 167-178.

Shintani, T. and Klionsky, D.J. 2004. Autophagy in health and disease: A double-edged sword. Science 306: 990-995.

Singh, S.B., Davis, A.S., Taylor, G.A., and Deretic, V. 2006. Human IRGM induces autophagy to eliminate intracellular mycobacteria. Science 313: 1438-1441.

Suriapranata, I., Epple, U.D., Bernreuther, D., Bredschneider, M., Sovarasteanu, K., and Thumm, M. 2000. The breakdown of autophagic vesicles inside the vacuole depends on Aut4p. J. Cell Sci. 113: 4025-4033.

Suzuki, K. and Ohsumi, Y. 2007. Molecular machinery of autophagosome formation in yeast, Saccharomyces cerevisiae. FEBS Lett. 581: 2156-2161.

Suzuki, K., Kirisako, T., Kamada, Y., Mizushima, N., Noda, T., and Ohsumi, Y. 2001. The pre-autophagosomal structure organized by concerted functions of $A P G$ genes is essential for autophagosome formation. EMBO J. 20: 5971-5981.

Suzuki, K., Kubota, Y., Sekito, T., and Ohsumi, Y. 2007. Hierarchy of Atg proteins in pre-autophagosomal structure organization. Genes Cells 12: 209-218. 
Swanson, M.S. and Fernandez-Moreira, E. 2002. A microbial strategy to multiply in macrophages: The pregnant pause. Traffic 3: 170-177.

Takacs-Vellai, K., Vellai, T., Puoti, A., Passannante, M., Wicky, C., Streit, A., Kovacs, A.L., and Muller, F. 2005. Inactivation of the autophagy gene bec-1 triggers apoptotic cell death in C. elegans. Curr. Biol. 15: 1513-1517.

Takeshige, K., Baba, M., Tsuboi, S., Noda, T., and Ohsumi, Y. 1992. Autophagy in yeast demonstrated with proteinase-deficient mutants and conditions for its induction. J. Cell Biol. 119: 301-311.

Tallóczy, Z., Jiang, W., Virgin, H.W.T., Leib, D.A., Scheuner, D., Kaufman, R.J., Eskelinen, E.-L., and Levine, B. 2002. Regulation of starvation- and virus-induced autophagy by the eIF2 $\alpha$ kinase signaling pathway. Proc. Natl. Acad. Sci. 99: 190-195.

Tanida, I., Minematsu-Ikeguchi, N., Ueno, T., and Kominami, E. 2005. Lysosomal turnover, but not a cellular level, of endogenous LC3 is a marker for autophagy. Autophagy 1: 8491.

Teter, S.A., Eggerton, K.P., Scott, S.V., Kim, J., Fischer, A.M., and Klionsky, D.J. 2001. Degradation of lipid vesicles in the yeast vacuole requires function of $\mathrm{Cvt17}$, a putative lipase. J. Biol. Chem. 276: 2083-2087.

Thorburn, J., Moore, F., Rao, A., Barclay, W.W., Thomas, L.R., Grant, K.W., Cramer, S.D., and Thorburn, A. 2005. Selective inactivation of a Fas-associated death domain protein (FADD)-dependent apoptosis and autophagy pathway in immortal epithelial cells. Mol. Biol. Cell 16: 1189-1199.

Tooze, J., Hollinshead, M., Ludwig, T., Howell, K., Hoflack, B., and Kern, H. 1990. In exocrine pancreas, the basolateral endocytic pathway converges with the autophagic pathway immediately after the early endosome. J. Cell Biol. 111: 329345.

Tsukada, M. and Ohsumi, Y. 1993. Isolation and characterization of autophagy-defective mutants of Saccharomyces cerevisiae. FEBS Lett. 333: 169-174.

Vabulas, R.M. and Hartl, F.U. 2005. Protein synthesis upon acute nutrient restriction relies on proteasome function. Science 310: 1960-1963.

Wang, Q.J., Ding, Y., Kohtz, S., Mizushima, N., Cristea, I.M., Rout, M.P., Chait, B.T., Zhong, Y., Heintz, N., and Yue, Z. 2006. Induction of autophagy in axonal dystrophy and degeneration. J. Neurosci. 26: 8057-8068.

Wooten, M.W., Hu, X., Babu, J.R., Seibenhener, M.L., Geetha, T., Paine, M.G., and Wooten, M.C. 2006. Signaling, polyubiquitination, trafficking, and inclusions: Sequestosome $1 /$ p 62 's role in neurodegenerative disease. J. Biomed. Biotechnol. 2006: 62079. doi: 10.1155/JBB/2006/62079.

Xiong, Y., Contento, A.L., and Bassham, D.C. 2007a. Disruption of autophagy results in constitutive oxidative stress in Arabidopsis. Autophagy 3: 257-258.

Xiong, Y., Contento, A.L., Nguyen, P.Q., and Bassham, D.C. 2007b. Degradation of oxidized proteins by autophagy during oxidative stress in Arabidopsis. Plant Physiol. 143: 291-299.

Yan, L., Vatner, D.E., Kim, S.J., Ge, H., Masurekar, M., Massover, W.H., Yang, G., Matsui, Y., Sadoshima, J., and Vatner, S.F. 2005. Autophagy in chronically ischemic myocardium. Proc. Natl. Acad. Sci. 102: 13807-13812.

Yang, Z., Huang, J., Geng, J., Nair, U., and Klionsky, D.J. 2006. Atg2 2 recycles amino acids to link the degradative and recycling functions of autophagy. Mol. Biol. Cell 17: 5094-5104.

Yorimitsu, T., Nair, U., Yang, Z., and Klionsky, D.J. 2006. Endoplasmic reticulum stress triggers autophagy. I. Biol. Chem. 281: 30299-30304.

Yoshimoto, K., Hanaoka, H., Sato, S., Kato, T., Tabata, S., Noda,
T., and Ohsumi, Y. 2004. Processing of ATG8s, ubiquitinlike proteins, and their deconjugation by ATG4s are essential for plant autophagy. Plant Cell 16: 2967-2983.

Yu, W.H., Cuervo, A.M., Kumar, A., Peterhoff, C.M., Schmidt, S.D., Lee, J.H., Mohan, P.S., Mercken, M., Farmery, M.R., Tjernberg, L.O., et al. 2005. Macroautophagy-A novel $\beta$ amyloid peptide-generating pathway activated in Alzheimer's disease. J. Cell Biol. 171: 87-98.

Yu, L., Wan, F., Dutta, S., Welsh, S., Liu, Z., Freundt, E., Baehrecke, E.H., and Lenardo, M. 2006. Autophagic programmed cell death by selective catalase degradation. Proc. Natl. Acad. Sci. 103: 4952-4957.

Yue, Z., Jin, S., Yang, C., Levine, A.J., and Heintz, N. 2003. Beclin 1, an autophagy gene essential for early embryonic development, is a haploinsufficient tumor suppressor. Proc. Nat1. Acad. Sci. 100: 15077-15082.

Zeng, X., Overmeyer, J.H., and Maltese, W.A. 2006. Functional specificity of the mammalian Beclin-Vps34 PI 3-kinase complex in macroautophagy versus endocytosis and lysosomal enzyme trafficking. J. Cell Sci. 119: 259-270.

Zhang, H., Monken, C.E., Zhang, Y., Lenard, J., Mizushima, N., Lattime, E.C., and Jin, S. 2006. Cellular autophagy machinery is not required for vaccinia virus replication and maturation. Autophagy 2: 91-95.

Zhang, Y., Qi, H., Taylor, R., Xu, W., Liu, L.F., and Jin, S. 2007. The role of autophagy in mitochondria maintenance: Characterization of mitochondrial functions in autophagy-deficient S. cerevisiae strains. Autophagy 3: 337-346.

Zhao, Z., Thackray, L.B., Miller, B.C., Lynn, T.M., Becker, M.M., Ward, E., Mizushima, N., Denison, M.R., and Virgin, H.W.T. 2007. Coronavirus replication does not require the autophagy gene ATG5. Autophagy 3: 581-585. 


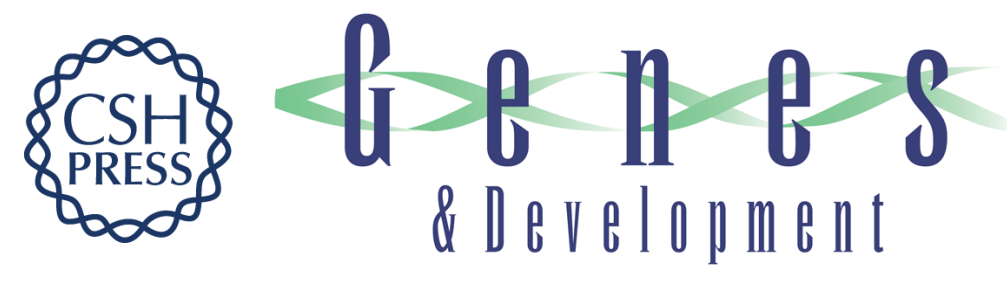

\section{Autophagy: process and function}

Noboru Mizushima

Genes Dev. 2007, 21:

Access the most recent version at doi:10.1101/gad.1599207

References This article cites 158 articles, 73 of which can be accessed free at: http://genesdev.cshlp.org/content/21/22/2861.full.html\#ref-list-1

License

Email Alerting Receive free email alerts when new articles cite this article - sign up in the box at the top Service right corner of the article or click here.

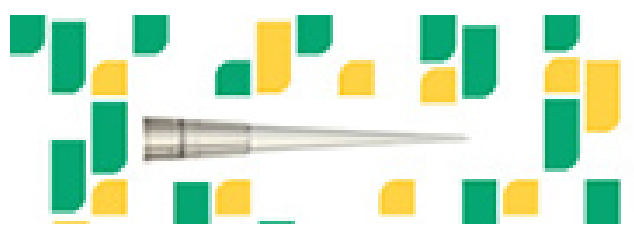

Focused on your science. 